Recibido: 08/06/2020 --- Aceptado: 17/08/2020 --- Publicado: 15/11/2020

\title{
JOKER, O LA SALVACIÓN DE LOS DESECHOS
}

\section{JOKER, OR THE SALVATION OF THE DESPOILS}

Johnny Gavlovski E. ${ }^{1}$. Universidad Metropolitana. Venezuela.

EJGavlovsku@unimet.edu.ve

\section{RESUMEN}

El éxito de la película "Joker" (2019) ha venido acompañado de inquietud e incertidumbre. Tanto por la manera diferente en la que el filme trata a un personaje que la cultura pop ha encasillado en el rol de payaso malvado y demente que debe ser detenido a todo trance; como por la necesidad comercial y artística de comprender las causas de ese éxito o los entresijos argumentales del filme y de sus personajes. La sensación es que al payaso diabólico se le concede por vez primera el derecho a una motivación comprensible. Esto no es cierto: el personaje ha contado históricamente con profundas y bien argumentadas motivaciones. Es la locura del personaje -que predata a su encuentro con Batman y su célebre caída a la cuba de ácido- lo que no recibió una justificación más allá del defecto de nacimiento hasta el mítico Joker de Heath Ledger, que le aportó un cuadro típicamente freudiano. Phoenix y Phillips lo llevan un paso más allá, ahondando en las raíces de la locura y en la responsabilidad colectiva de la sociedad por aquellos a quienes el sistema no logra salvar. Se le permite a este Joker/Guasón protagonizar al fin su propia cinta, no como una excusa del comportamiento antisocial, sino como una explicación de las muy complejas causas que lo motivan frente a las comparativamente simples soluciones de lo que la sociedad llama orden público. Y como un aviso de que la gestión humana, forma parte también del desarrollo sostenible de una sociedad funcional.

PALABRAS CLAVE: Joker - Joaquin Phoenix - Comunicación sostenible - Sociedad funcional - Gestión humana

\section{ABSTRACT}

The success of "Joker" (2019) has been followed by unease and uncertainty. So much for the different way in which the film depicts a character pop culture has pigeonholed in the role of evil and insane clown who must be stopped at all costs; as for the commercial and artistic need to understand the causes of its success or the

${ }^{1}$ Escritor. Docente UNIMET. Psicólogo clínico y psicoanalista miembro de la Asociación Mundial de Psicoanálisis. Coordinador de la Red de Cine y Psicoanálisis para la Nueva Escuela Lacaniana. Docente de la Universidad Metropolitana de Caracas. 
plot intricacies of the film and its characters. The general feeling is that the devilish clown is given the right to an understandable motivation for the first time. This is not true: the character has historically had deep and well-written motivations. It is the madness of the character - who predates his encounter with Batman and his famous fall into the acid vat- what receives no justification beyond birth-right until the legendary Joker by Heath Ledger, who gave him a typically Freudian personality frame. Phoenix and Phillips take it one step further, delving into the roots of insanity and the collective responsibility of society for those whom the system fails to save. This Joker is allowed to finally star in his own film, not as an excuse for antisocial behavior, but as an explanation of the very complex causes that motivate him compared to the comparatively simple solutions of what society calls public order. And as a warning that sustainable human management is part of a fully functional society.

KEY WORDS: Joker - Joaquin Phoenix - Sustainable Communication - Functional society - Human Management

\section{JOKER, OU A SALVAÇÃO DO LIXO}

\section{RESUMO}

O sucesso do filme "Joker" (2019) foi acompanhado de inquietação e incerteza. Tanto pela forma diferente na que um filme trata ao personagem que a cultura pop classificou no papel de palhaço mau e louco que deve ser detido a todo custo; quanto pela necessidade comercial e artística de compreender as causas desse sucesso ou os detalhes argumentais do filme e seus personagens. A sensação é que ao palhaço diabólico é concedido pela primeira vez o direito a uma motivação compreensível. Isto não é o certo: o personagem contou historicamente com profundas e bem argumentadas motivações. É a loucura do personagem - o que é anterior ao seu encontro com o Batman e sua célebre queda no tanque de ácido- o que não recebeu uma justificativa além do defeito de nascimento até o mítico Joker do Heath Ledger, que deu a ele uma personalidade tipicamente freudiana. Phoenix e Phillips levam isto além, aprofundando nas raízes da loucura e na responsabilidade coletiva da sociedade por aqueles a quem o sistema não consegue salvar. É permitido a este Joker estrelar finalmente seu próprio filme, não como uma desculpa do comportamento anti social, mas como uma explicação das muito complexas causas que o motivam frente às comparativamente simples soluções do que a sociedade chama de ordem pública. E como um aviso de que a gestão humana, forma parte também do desenvolvimento sustentável de uma sociedade funcional.

PALAVRAS CHAVE: Joker - Joaquin Phoenix - Comunicação sustentável Sociedade funcional - Gestão humana 


\title{
Cómo citar el artículo:
}

Gavlovski E. J. (2020). Joker, o la salvación de los desechos. [Joker, or the salvation of the despoils]. Revista de Comunicación de la SEECI, 53, 69-81. doi: https://doi.org/10.15198/seeci.2020.53.69-81

Recuperado de http://www.seeci.net/revista/index.php/seeci/article/view/652

\section{INTRODUCCIÓN}

\author{
Ponte el traje \\ y empólvate el rostro. \\ La gente paga y aquí quiere reír, \\ y si Arlequín te roba a Colombina, \\ iríe, Payaso, y todos te aplaudirán!
}

\section{Aria Vesti la Giubba (1892) \\ ópera Pagliacci, de Ruggiero Leoncavallo.}

Podemos ver un animal amarrado, golpeado, maltratado, llevado al matadero. Podemos compadecernos y no faltará alguien que increpe: i"Qué importa!, acaso, ¿tú no comes carne?" Podemos ver aves enjauladas, sometidas a tratamiento hormonal, violentadas en su naturaleza, atrapadas en estrechas jaulas sólo con el fin de producir para nosotros. Basta voltear la mirada, lamentarse de la violencia humana y seguir degustando un exquisito cordon blue o unos huevos benedictinos. Podemos incluso ver el drama de los desplazados, de las guerras, las matanzas, los ataques terroristas por la TV, internet, en nuestros dispositivos móviles. O escuchar impávidos del negacionismo del holocausto nazi, o del manejo actual de las conveniencias económicas anteponiéndolo a un tomar partido frente a los abusos de los derechos humanos. Todo eso está lejos, no nos toca, es parte del fenómeno del mass media que ofrece espectáculos diversos, entre los cuales destaca un terror tan taquillero. Basta el fin de la película, o el off de nuestros dispositivos para poner fin al acto de consciencia. Lo ominoso está afuera, en lo extranjero, apartado, segregado, y eso tranquiliza.

La historia de nuestro mundo occidental está llena de relatos del impacto de la revolución industrial en nuestras vidas. Por ejemplo, revisamos la literatura inglesa y en la obra de Ch. Dickens, comprendemos el lugar de desecho que tuvo el cachorro humano. Se necesitó un Jean Jacques Rousseau, para elevarlo a la dignidad de la Cosa, como diría Lacan, basado en la obra del filósofo alemán Georg Simmel; entendiendo la Cosa como aquello de mí, fuera de mí, lo más íntimo en el exterior, lo éxtimo.

Así la dignidad de la infancia, es decir, la belleza de la infancia que debe ser respetada, se inserta como una virtud en nuestra sociedad, en un marco simbólico 
del cual, somos parte; y dónde se regulariza la actividad sexual en una institución llamada matrimonio ${ }^{2}$

\section{OBJETIVOS}

El objetivo de este artículo es diseccionar el último fenómeno cinematográfico "Joker" (2019) a fin de dar una explicación psicológica y culturalmente razonada de su contenido, su mensaje y su protagonista. Una explicación que permita entender el alcance del fenómeno y la verdadera extensión dramática de sus personajes y escenas, a fin de facilitar la comprensión de los elementos comunicativos -0 no comunicativos- que han creado este fenómeno viral y cinematográfico, en un entorno de estrenos palomiteros y supertaquilleros donde la preocupación por la calidad queda remitida a la implementación del último FX digital, relegando a la actuación y al guion bien escrito al cubo de la basura de la historia del cine.

\section{METODOLOGÍA}

Me propongo llevar a cabo un concienzudo análisis psico-social sobre los hechos y personajes retratados en la película. Sus motivaciones, bagaje, y relación con la sociedad imperante hasta las reacciones surgidas de esta relación. Todo ello casado con la revisión de los antecedentes del tándem payaso-dramatismo como poderoso motor de denuncia y revisión de nuestras contradicciones colectivas y personales, así como los precedentes relevantes de denuncia social en el plano de la ética imperante y el ostracismo como técnica de protección de las sociedades frente a quienes enfrentan aquello que estas no quieren confrontar.

\section{DISCUSIÓN}

Por supuesto, hoy en día, en nuestro mundo de bebes de probeta, de inseminación artificial, de derechos humanos, la palabra "bastardo" ha perdido su valor; pero en otros tiempos, no muy lejos por cierto, implicaba una diferencia, incluso, una mancha en la honorabilidad del hogar. Con que brillantez, el artista belga Felicien Rops, en su obra "La Parodia Humana"3, supo denunciar al representar al digno pater familias en su encuentro con la enfermedad venérea, para luego regresar a su hogar, a ocupar su lugar, y contagiar a su familia. Esa sífilis de la que nadie se hacía cargo y siempre era causa de Otro: los franceses la llamaban el mal napolitano, los rusos la enfermedad polaca, los polacos la enfermedad alemana.

2 Sugerimos la lectura de Miller, Jacques Alain La Salvación por los desechos http://www.nelmexico.org/articulos

3 Felicien, R. La parodia humana (1878-1881) acuarela, pastel, tiza $(22,5 \times 15 \mathrm{~cm})$ Musee Rops, Namur. 


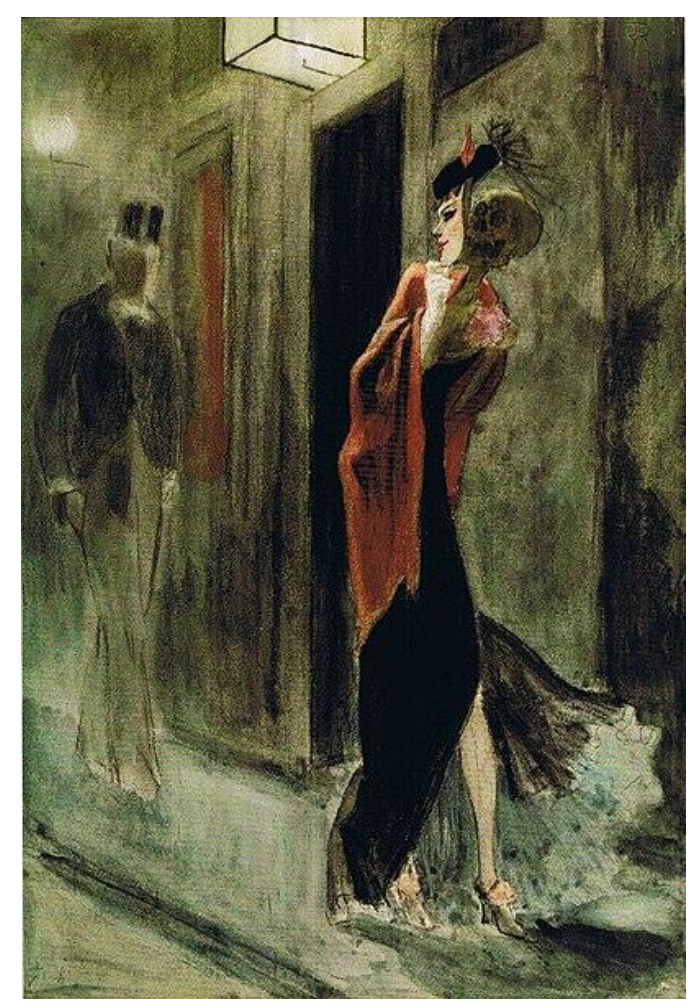

Figura 1: Felicien Rops

La parodia humana (1878-1881)

Era el desliz del progenitor, y tal como los niños espartanos deformes, que amenazaban el ideal cultural, eran expulsados, alejados del paraíso de la aceptación.

Así se trató lo diferente. Así se sigue tratando hoy en día.

Y a veces el pecado de los padres regresa como lo real del cuerpo, en eso que llamamos herencia, devolviéndonos de forma descarnada los fantasmas de nuestras pesadillas familiares. Henryk Ibsen los mostró en su obra "Espectros" Estrenada en 1882 , y prohibida desde entonces por haber tenido la osadía de mostrar lo que debe ocultarse: la historia del hijo que es alejado del hogar para no ser contaminado por los pecados del padre, y retorna para morir, pues la herencia no perdona. 


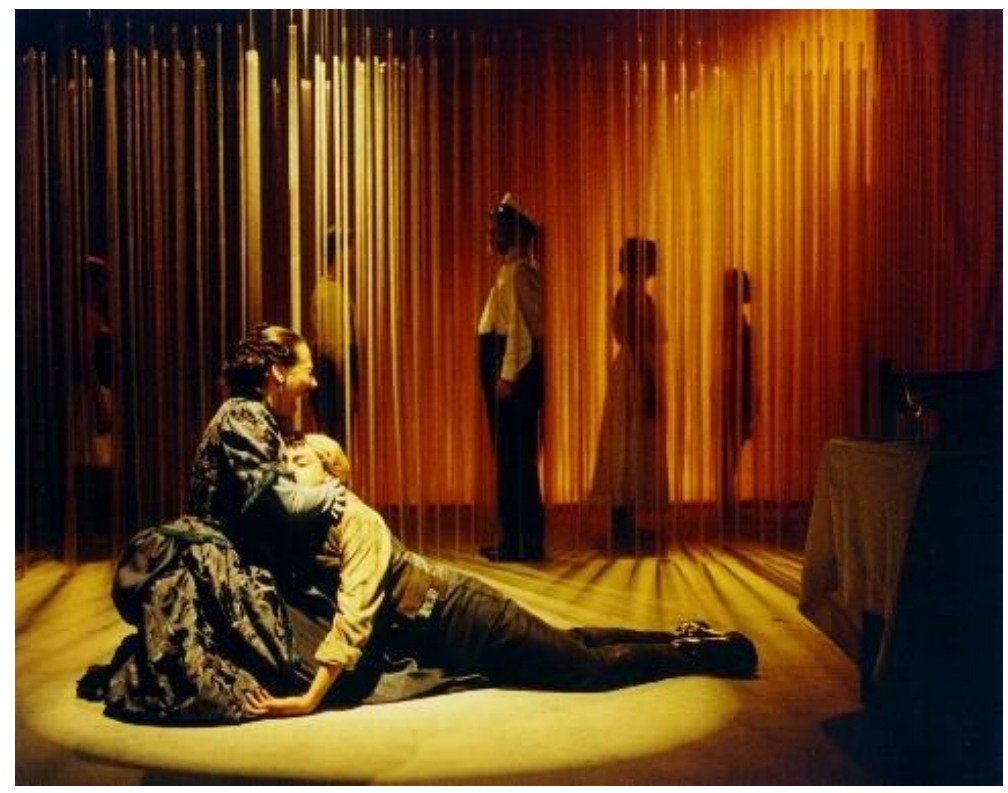

Figura 2: Espectros de $\mathrm{H}$ Ibsen

Foto Roland Streuli. Dirección Johnny Gavlovski. Sala Rajatabla, 1999

Todo esto nos lleva Joker (2019), guión creado para cine por Todd Phillips y Scott Silver, y dónde un profundo suspiro de alivio, calma el horror que recorre a los espectadores, cuando entienden que el protagonista, Arthur Fleck, no comete un terrible matricidio, sino que por el contrario, hace justicia con una mujer que no es su madre, y que además permitió lo abusaran de niño. Es decir, el crimen en su connotación moral aparece en nuestros ojos matizado, elevado a la categoría de pretexto; entrando así en una serie de justificaciones del mismo tenor, desde el momento mismo en que se entiende porque Fleck se comporta como lo hace.

El crimen está justificado, pareciera la primera lectura de este film, pero quedarnos en eso nos lleva a olvidar que el film dirigido por Phillips, conlleva una lectura de mayor gravedad: Todos somos responsables del malestar de nuestra cultura.

Los primeros minutos del film, ya dejan clara la tesis. Este hombre, que cuida a una madre, que no es tal; que espera a un padre, que no llega; que trata de vivir de la forma más honesta en el oscuro inframundo de Ciudad Gótica, es burlado, golpeado, vejado, terminado en el piso como resto de la violencia urbana. 


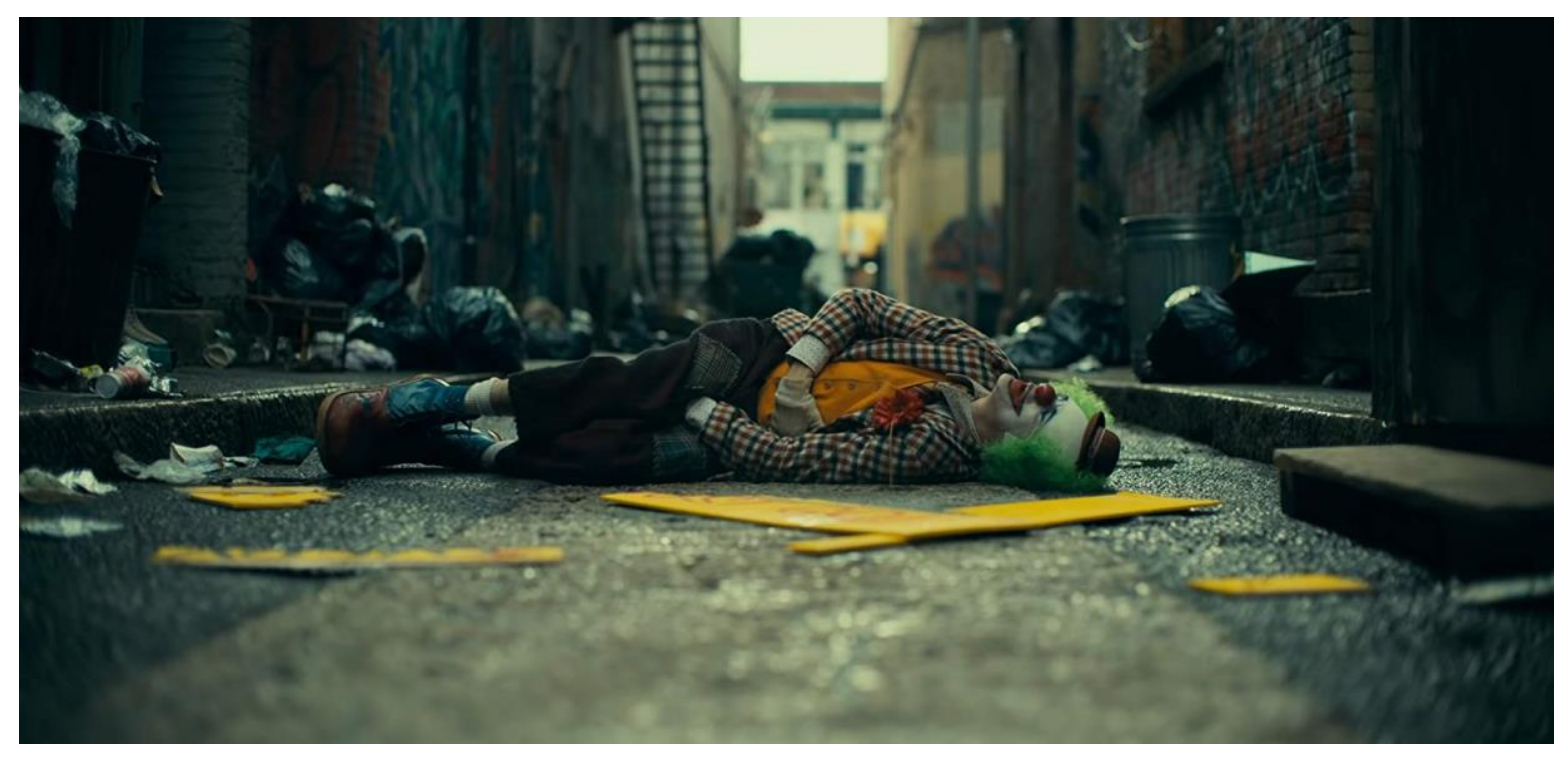

Figura 3: Escena de Joker (2019) Dirección Todd Phillips

He ahí el inicio de la tesis de esta obra. Y digo obra como el resultado de un saber hacer de quienes la construyeron, empezando por un señor actor como lo es Joaquín Phoenix, quien logra lo que muchos consideramos imposible: colocarse a la par del mítico Guasón de Heath Ledger. Ambos artistas alcanzan el Olimpo de las artes, desde espacios diferentes: mientras Ledger es el señor del Tártaro, el magistral Phoenix marca el inicio del descenso al inframundo. Para ello, lleva la actuación a otro nivel, a una composición de cuerpo y estructura interpretativa como pocas veces hemos visto en el cine, excepto en aquellos artistas que pasan al nivel de leyenda.

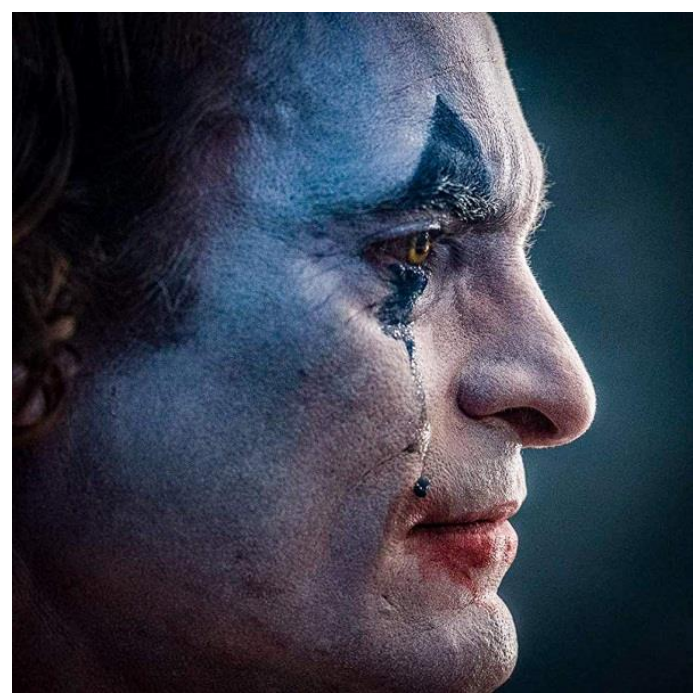

Figura 4: Joaquín Phoenix como "Arthur Fleck"

\section{"TAL VEZ UN POCO DE DECENCIA"}

¿Cómo no empatizar con un personaje que lo que pide a gritos es un mínimo de dignidad? 
Arthur Fleck: "Sé que parece extraño, no quiero hacerte sentir incómodo, no sé por qué todos son tan groseros, no sé por qué lo eres: No quiero nada de ti. Tal vez un poco de calidez, tal vez un abrazo papá, tal vez un poco de decencia común" ${ }^{\prime 4}$

Fleck intenta insertarse en el mundo a través del semblante de la comedia, encarnando el deseo de la madre

Arthur Fleck: "Mi madre siempre me dice que sonría y ponga una cara feliz. Ella me dijo que tenía un propósito: traer risas y alegría al mundo"s, es decir, un Joker, un comodín, un significante al servicio del deseo de Otro, es decir, que toma "su valor según convenga al jugador que lo posee", ergo, un objeto del Otro, encajando perfectamente así en el origen de las psicosis tal como explicita Lacan en su primera aproximación a éstas. Un niño devorado por el deseo de la madre, ante la ausencia (forclusión) de un padre (o quien ejerza dicha función) que le ponga límites.

Así Fleck se hace existir en ese extremo del payaso, en ese arquetipo trágico que Ruggiero Leoncavallo eternizara en su opera Pagliacci, en la voz de Canio, el engañado payaso.

\author{
Original en Italiano \\ Recitar! Mentre preso dal delirio, \\ non so più quel che dico, \\ e quel che faccio! \\ Eppur è d'uopo, sforzati! \\ Bah! sei tu forse un uom? \\ Tu se' Pagliaccio! \\ Vesti la giubba, \\ e la faccia infarina. \\ La gente paga, e rider vuole qua.
}

\author{
Traducción al español 7 \\ iActuar! iMientras preso del delirio, \\ no sé ya lo que digo \\ ni lo que hago! \\ Y sin embargo, es necesario... iesfuérzate! \\ iBah! ¿Acaso eres tú un hombre? \\ iEres Payaso! \\ Ponte el traje \\ y empólvate el rostro. \\ La gente paga y aquí quiere reír,
}

Pero si bien el espíritu verista de Leoncavallo antecede a la obra de Phillips \& Silver, en el Canio del músico napolitano no está la denuncia a un sistema ineficiente para con sus ciudadanos, donde insertarse implica negar su propia tragedia. Así Fleck escribe en su cuaderno: "La peor parte de tener una enfermedad mental es que la gente espera que te comportes como si no lo hicieras"

Fleck pide ayuda y no la consigue. Y no sólo por la inoperancia de un departamento de salud bajo una dirigencia corrupta, sino que para el momento, se desconocía que su risa patológica era consecuencia de una epilepsia gelástica, frente a lo cual los fármacos nada podrían hacer excepto a través de la extirpación

\footnotetext{
${ }^{4}$ https://www.imdb.com/title/tt7286456/characters/nm0001618?ref $=\mathrm{ttfc}$ fc cl t1

${ }^{5}$ Op. Cit.

${ }^{6}$ https://www.google.com/search?client=firefox-b-d\&q=comod\%C3\%ADn

7 Extracto del aria "Vesti la Giubba", ópera Pagliacci de Ruggiero Leoncavallo, traducción tomada de https://es.wikipedia.org/wiki/Vesti la giubba Recuperado 27 Octubre, 2019
} 
quirúrgica de su etiología en un tumor en el hipotálamo. Por eso ríe, y no como Canio que "i Ríe del dolor que te envenena el corazón!"8 Aquí la dimensión de la risa es la de la evidencia de que algo no funciona, algo no va en su cuerpo, algo que se entrelaza con aquello incapaz de ser verbalizado: la angustia. Lo lamentable es que Arthur Fleck, no tiene los recursos para hacer con ésta; y mucho menos, para echar mano a esa formación del inconsciente llamada chiste, o para defenderse a través de la sublimación. Melanie Klein nos enseñó como ante la inoperancia de ésta, lo que resta es la inhibición en el sujeto. Pero aun así, Fleck logra un nombre, un nombre para su goce: Joker

\section{Arthur Fleck: Murray, una pequeña cosa?}

\section{Murray Franklin: ¿Sí?}

\section{Arthur Fleck: Cuando me invites a salir, ¿puedes presentarme como Joker?9}

Ahí su intento de insertarse, de sublimar a través de la comedia. Al decir de J-A Miller: "Lo que se llama sublimación efectúa una socialización del goce. El goce es socializado, es decir, integrado al lazo socia/"10

Sin embargo, a diferencia de Canio quien "Transforma en bromas la congoja y el Ilanto; en una mueca, los sollozos y el dolor"11 ; Fleck está imposibilitado para ello. De nuevo la expulsión, la burla, la transferencia sobre Murray Franklin para "salvar al padre" y encontrar ese espacio "agujereado", "inexistente"; y el consecuente no reconocimiento como hijo, como "ser" que no sea como objeto de uso por el Otro. Así lo fue en su infancia: no fue niño, sino una necesidad de Penny Fleck, no un niño con derechos, sino un objeto de uso y abuso por parte de los hombres, a quienes a su vez ella se ofrecía como objeto de satisfacción. $Y$ ahí es comprendemos porque el goce de Joker, no es "elevado a la dignidad de la Cosa"12, sino "rebajado a la indignidad del desecho"13, a la imposibilidad de sublimación.

Entonces mientras corre el discurso del film, el inconsciente queda a cielo abierto, y lo real lacaniano, ese inatrapable que es angustia e imposibilidad de significación, golpea no sólo a Arthur Fleck, y su mundo, sino al espectador de forma violenta e implacable. Y el Joker declara: "Durante toda mi vida, no supe si realmente existía. Pero yo sí, y la gente comienza a darse cuenta" La vía, la violencia, el crimen al que fue empujado.

\footnotetext{
${ }^{8}$ Ibid

${ }^{9}$ https://www.imdb.com/title/tt7286456/characters/nm0001618?ref $=\mathrm{ttfc}$ fc cl t1

10 Miller, J. A. La Salvación por los desechos http://www.nel-mexico.org/articulos Recuperado 26 de octubre 2019

${ }^{11}$ Leoncavallo, R. "Tramuta in lazzi lo spasmo ed il pianto/ in una smorfia il singhiozzo e "l dolor" Op cit

${ }^{12}$ Lacan, J. (1988), La ética del psicoanálisis, Libro 7, Clase XII Edit Paidós. Buenos Aires. Pág. 138

${ }^{13}$ Ibid
} 


\title{
5. CONCLUSIÓN
}

\author{
"En ese cuerpo pasan cosas imprevistas"14 \\ La razón por la que danzamos \\ es porque existen muchas cosas \\ que no entendemos \\ Kazuo Ohno
}

El catarismo fue una corriente herética del siglo XII, que alarmó a la Iglesia católica dados algunos planteamientos, entre ellos, la manera en que asumieron la idea dualista de la interminable lucha entre el Bien y el Mal. Lo particular de ellos, es que jugaban esa batalla en el propio cuerpo. Así, el Bien, los orientaba a "la pureza y la luz, un mundo de lo verdadero, del buen Creador original, cuya creación había sido mancillada por la intervención del creador malo, del Demiurgo ${ }^{15}$, quien había creado el mundo y todo lo material que éste implica; y como consecuencia de ello: "la putrefacción, es decir, la transformación", ergo, "El mal está en la materia"16

En consecuencia, no puede extrañarnos entonces que Joker surja del cuerpo, de un cuerpo danzante. "En ese cuerpo pasan cosas imprevistas... y pasan cosas imprevistas justamente porque el cuerpo, el cuerpo del que hablamos en el psicoanálisis, es un cuerpo perturbado, modificado, profundamente marcado por el significante, es decir por el Otro y por lo real"17 Lacan lo llamó "mortificación del cuerpo", y desarrolló esa idea hasta llegar a comprender el cuerpo como "afectado por el Otro, afectado por la articulación significante, afectado por las marcas significantes que van a subjetivar el cuerpo y la imagen"18 Así, podemos entender al Joker desde el acontecimiento del cuerpo.

De esta manera, desde la mortificación del cuerpo del actor Phoenix ${ }^{19}$ hasta la del personaje Arthur Flake, darán ese síntoma llamado Joker. Un personaje que nace literalmente del lenguaje del cuerpo, en la improvisación del actor, a través de la música de Hildur Guðnadóttir. Pareciera inspirado en las danzas/performance: Ankoku butō (暗黒舞踏), la danza de la oscuridad, creadas por Kazuo Ohno y Tatsumi Hijikata (1950)

\footnotetext{
14 Tarrab, M citando a J-A Miller en su curso de 1999, http://pepsic.bvsalud.org Recupe 27 Oct 2019

${ }^{15}$ Lacan, J.(1955) El Seminario, Libro 7, La ética del psicoanálisis. Edit Paidós, Buenos Aires. Pág.153

${ }^{16}$ Op cit Pág 154

17 Tarrab, M Op cit

${ }^{18}$ Ibid

${ }^{19}$ N.A.: quien adelgazo 23 kilos en 4 meses para poder interpretar su rol
} 


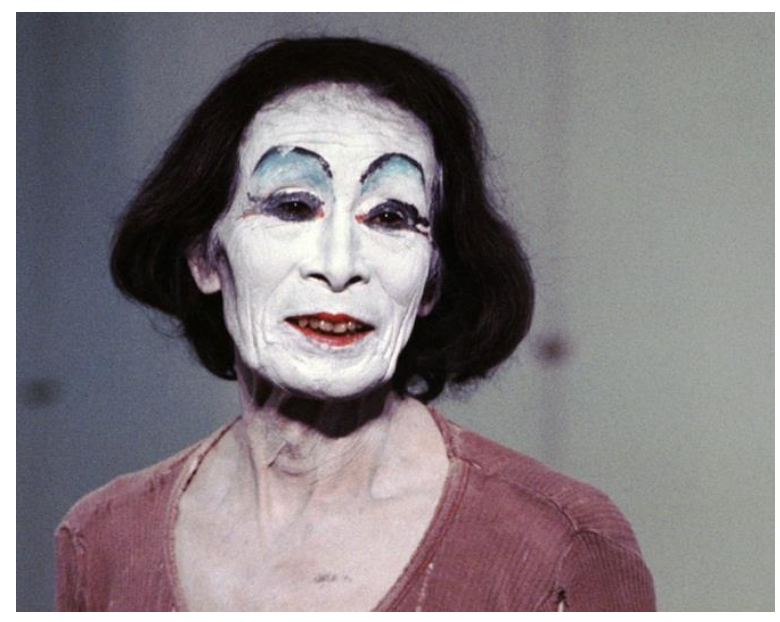

Figura 5: Kazuo Ohno(1906-2010)

Una danza de ruptura, nacida "dentro del contexto de posguerra en un Japón en ese entonces devastado (... donde había) proliferación de espacios en los que se revelaban, por un lado, la caída de los valores que anteriormente habían regido la vida cotidiana y, por otro, la necesidad y el deseo de creación de algo nuevo"zo

La etimología de Ankoku butō viene de Buyo "palabra neutra para danza y tiene la raíz de las palabras "brincando" o "saltando" que Tatsumi Hijikata "decidió nombrarla sólo como: Butoh "para distinguirla tanto de la danza occidental como de la danza tradicional japonesa" amén que el sufijo "toh implica pisar firmemente, arraigarse a la tierra" De esta manera, mientras Buyoh, "es lo ascendente, Butoh es 10 descendente" 21 , pudiéndose interpretar como "la danza del descendimiento en la oscuridad, entendiendo ésta, de acuerdo con Natzue Nakajima en "aquello sin forma, aquello que no se puede expresar en palabras"22 De nuevo, lo Real insiste.

${ }^{20}$ Pérez Monjaraz, Nayeli La desterritorialización del cuerpo. Una reflexión acerca de la danza Butoh http://reflexionesmarginales.com/3.0/la-desterritorializacion-del-cuerpo-una-reflexion-acerca-de-la-

danza-butoh Reflexiones Marginales - ISSN 2007-8501 Otorgado por el Centro Nacional del ISSN Recuperado 27 octubre, 2019

${ }^{21}$ Op cit

22 https://es.wikipedia.org/wiki/ Recuperado 27 octubre, 2019 


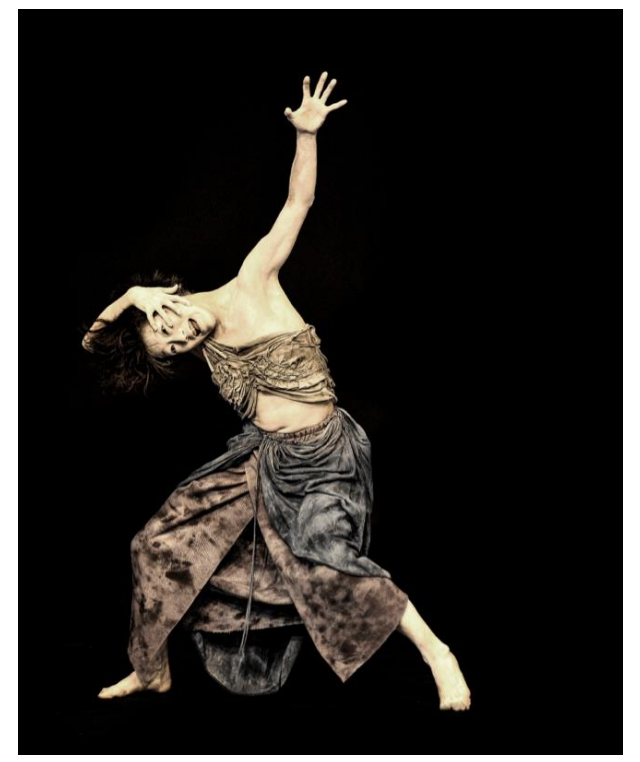

Figura 5: Danza-butoh ${ }^{23}$

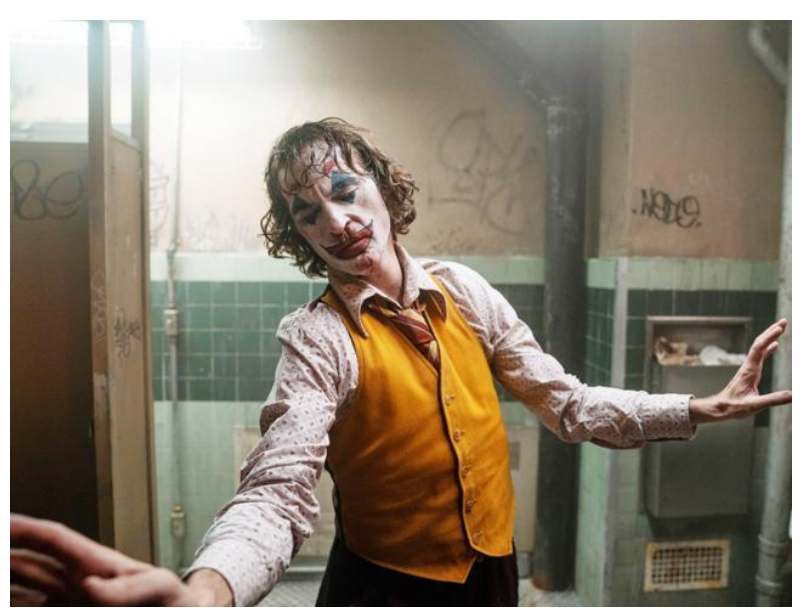

Figura 6: Joker (2019) Dir: Todd Phillips

Cual difunto, Arthur Flake parece descender al Hades. El paisaje de oscuridad, violencia, fuego y muerte sirven como escenario para la escena del accidente final. Podemos creerlo muerto, resto, sobre el capote del carro; pero cual siniestro fénix será rescatado de sus cenizas por otros, semejantes, que cual imagen en el espejo, le devuelven una imagen grandiosa de sí, descubriendo un mundo apocalíptico, como aquel donde surgiera el Ankoku butō.

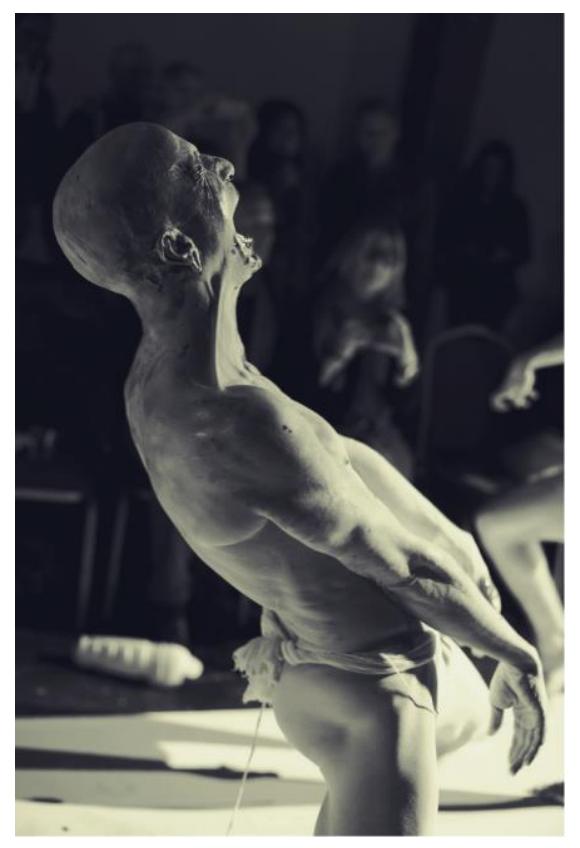

Figura 5: Danza-butoh ${ }^{24}$

\footnotetext{
${ }^{23}$ Reflexiones Marginales. Op cit

${ }^{23}$ Ibid

${ }^{24}$ Ibid
} 
Pero ahora el Joker no danza; ahora contempla, contempla y actúa desde el foso de la locura; sin darse cuenta que a través del anhelado reconocimiento del Otro, seguirá siendo objeto de uso de quienes necesitan un payaso triste, una marioneta populista.

\section{BIBLIOGRAFÍA}

Miller, J.-A. (2010). La Salvación por los desechos. Radar, 56. Recuperado de http://www.nel-mexico.org/articulos/seccion/radar/edicion/61/59/La-Salvacionpor-los-desechos

Leoncavallo, R. (1892). Tramuta in lazzi lo spasmo ed il pianto/ in una smorfia il singhiozzo e 'I dolor. En: Leoncavallo, R. Vesti la giubba, Pagliacci. Milán, Italia: Leoncavallo, $\mathrm{R}$.

Lacan, J. (1988). La ética del psicoanálisis (Libro 7, Clase XII). Buenos Aires: Paidós.

Tarrab, M. (2004). Notas sobre el cuerpo. Metaphora, 3, 103-124. Recuperado de http://pepsic.bvsalud.org/scielo.php?script=sci arttext\&pid=S2072$\underline{06962004000100016}$

Pérez Monjaraz, N. (2016). La desterritorialización del cuerpo. Una reflexión acerca de la danza Butoh. Reflexiones Marginales, 36. Recuperado de: http://reflexionesmarginales.com/3.0/la-desterritorializacion-del-cuerpo-unareflexion-acerca-de-la-danza-butoh

\section{AUTOR}

\section{Johnny Gavlovski E.}

Escritor. Docente UNIMET. Psicólogo clínico y psicoanalista miembro de la Asociación Mundial de Psicoanálisis. Coordinador de la Red de Cine y Psicoanálisis para la Nueva Escuela Lacaniana. Docente de la Universidad Metropolitana de Caracas.

EJGavlovsku@unimet.edu.ve 